\title{
Spatial distribution and sociodemographic risk factors of malaria in Nigerian children less than 5 years old
}

\author{
Chigozie Louisa J. Ugwu, Temesgen Zewotir \\ School of Mathematics, Statistics and Computer Science, University of KwaZulu-Natal Westville Campus, \\ Durban, South Africa
}

\begin{abstract}
Malaria remains a leading cause of morbidity and mortality among children in Nigeria less than 5 years old (under-5). This study utilized nationally representative secondary data extracted
\end{abstract}

Correspondence: Chigozie Louisa J. Ugwu, School of Mathematics, Statistics and Computer Science, University of KwaZulu-Natal, Private Bag X 54001 Durban 4000, 3630 Westville, Durban, South Africa. Tel.: +27.834005235 .

E-mails: chigozie.ugwu@unn.edu.ng; 217075063@stu.ukzn.ac.za

Key words: Generalized linear mixed models; kriging; spatial variability; variogram; Nigeria-MIS; Nigeria.

Acknowledgements: The authors acknowledge MEASURE DHS for granting access them to the 2015 NMIS datasets. The first author appreciates the study leave and the opportunity granted by the University of Nigeria Nsukka, Nigeria. The first author also thanks the Department of Biostatistics, University of Washington, United States, for the training and the opportunity given to her during the 10th Annual Summer Institute in Statistics and Modeling in Infectious Diseases (SISMID).

Conflict of interests: The authors declare no potential conflict of interests.

Data Availability Statement: The analyzed dataset is freely available upon request from the Measure Demographic Health Survey (DHS) websites: www.dhsprogram.com/data/dataset/Nigeria.

Ethical statement: The 2015 Nigeria Malaria Indicator survey (NMIS)protocols were ethically cleared by the Nigeria Health Research Ethics Committee of the Federal Ministry of Health (NHREC) and the Internal Review Board of the ICF International in Calverton (USA). The study was based on a publicly available data obtained upon request through MEASURE DHS http://www.measuredhs.com and the consent to participate was not applicable, hence, an informed consent was provided by all the surveyed participants through their caregiver or parents prior to malaria test and the administration of questionnaires.

Received for publication: 28 September 2019

Accepted for publication: 28 January 2020.

(C) Copyright: the Author(s), 2020

Licensee PAGEPress, Italy

Geospatial Health 2020; 15:819

doi:10.4081/gh.2020.819

This article is distributed under the terms of the Creative Commons Attribution Noncommercial License (CC BY-NC 4.0) which permits any noncommercial use, distribution, and reproduction in any medium, provided the original author(s) and source are credited. from the 2015 Nigeria Malaria Indicator Survey (NMIS) to investigate the spatial variability in malaria distribution in those under5 and to explore the influence of socioeconomic and demographic factors on malaria prevalence in this population group. To account for spatial correlation, a Spatially Generalized Linear Mixed Model (SGMM) was employed and predictive risk maps was developed using Kriging. Highly significant spatial variability in under-5 malaria distribution was observed $(\mathrm{P}<0.0001)$ with a higher likelihood of malaria prevalence in this group in the Northwest and North-east of the country. The number of malaria infections increased with age, children aged between 49-59 months were found to be at a higher risk (Odds Ratio=4.680, 95\% $\mathrm{CI}=3.674$ to 5.961 at $\mathrm{P}<0.0001)$. After accounting for spatial correlation, we observed a strong significant association between the non-availability or non-use of mosquito bed-nets, low household socioeconomic status, low level of mother's educational attainment, family size, anaemia prevalence, rural type of residence and under-5 malaria prevalence. Faced with a high rate of under-5 mortality due to malaria in Nigeria, targeted interventions (which requires the identification of the child's location) may reduce malaria prevalence, and we conclude that socioeconomic impediments need to be confronted to reduce the burden of childhood malaria infection.

\section{Introduction}

Malaria continues to claim more than 400,000 lives each year as confirmed by the World Health Organization (WHO); in 2017, sub-Saharan Africa accounted for $80 \%$ of all cases and $90 \%$ of mortality due to malaria, $61 \%$ of which affecting children less than 5 years old (under-5) (WHO, 2018). Nigeria is a malariaendemic country in sub-Saharan Africa that has continuously recorded a high burden of malaria morbidity and mortality, especially in the under-5 group (WHO, 2018). Unlike many other subSaharan African countries, which have recorded a significant decline in malaria burden, the number of malaria cases in Nigeria increased with about 500,000 in 2017 (WHO, 2018). Although, the mortality rate decreased from about 202 deaths per 1,000 live births to 129 deaths per 1,000 live births between 2003 to 2013 in the under-5 group, statistics show that malaria accounts for approximately $30 \%$ of all deaths in this part of the population in Nigeria (Okonko et al., 2009; Okeke and Okeibunor, 2010; Onyiri, 2015). Resolution no. 3 of the 2030 Agenda for Sustainable Development Goals (SDGs) adopted by the United Nations (UN, 2018), concerns health, the worldwide improvement of which requires reduction of the malaria burden and its associated mortality as outlined by WHO (2019). Therefore, a better understanding of malaria distribution is of high relevance in 
Nigeria, as is investigating of the spatially influential factors that fully explain the patterns of under-5 infections.

A large number of studies on malaria prevalence in endemic regions have focused on the spatial patterns of its distribution (Diggle et al., 2002; Kazembe and Mathanga, 2016; Machault et al., 2010; Ayele et al., 2013; Samadoulougou et al., 2014; Ferrao et al., 2018; Umer et al., 2018). Each of these studies provide evidence that the geographical distribution of malaria is not spatially random. Evidence of links between malaria prevalence and environmental factors such as rainfall, temperature, the Normalized Difference Vegetation Index (NDVI) as well as socioeconomic factors, such as poverty have been observed. However, many of these studies give scant attention to spatial statistical approaches that not only focus on the descriptive aspect of the geostatistical methods, but also consider the relationship between malaria and the spatial effects of factors as those mentioned. Spatial analytical methods, in which the expected values and the covariance structures of the sample data are modelled based on accurate, inferential statistics have resulted in more efficient analyses (Zimmerman and Harville, 1991; Stroup et al., 1994). Furthermore, among these studies, only a few have considered analyzing data of the under-5 group (Diggle et al., 2002; Kreuel et al., 2008; Samadoulougou et al., 2014). It has been documented that sub-Saharan African countries bear the major burden of under- 5 mortality associated with malaria, so it is imperative to understand the spatial pattern of malaria disease distribution and risk factors across the high-risk areas with reference to the under $5 \mathrm{~s}$ via a nationally representative dataset. Only few studies have dealt with spatial modelling of malaria distribution in Nigeria and most of these studies have been largely based on hospital and clinical studies within communities and at the state level without much consideration of the under-5 group (Awolola et al., 2007; Onwujekwe et al., 2009; Kalu et al., 2012; Efe and Ojoh, 2013; Ebenezer et al., 2014; Weli and Efe, 2015). These studies found that the main environmental and socioeconomic factors associated with malaria distribution are rainfall, NDVI, temperature and low family income. Moreover, independent analysis of malaria prevalence with respect to socioeconomic, environmental and geographical factors with national-level data has been demonstrated (Idowu et al., 2009; Onwuemele, 2014; Adigun et al., 2015; Akpan et al., 2019; Onyiri, 2015). Their results show that day land surface temperature, NDVI and rainfall are the most important spatial predictors of malaria transmission. Further, using the first implemented 2010 Nigeria Malaria Indicator Survey (NMIS) data, Gawayan et al. (2014) and Adebayo et al. (2016) studied the comorbidity of malaria and non-malaria diseases among children in Nigeria using Bayesian geostatistical models. Their result shows a significant relationship between socioeconomic inequalities and the geographical differences in malaria distribution. Low socioeconomic status has proven to be a strong predictor of childhood deaths attributed to malaria and studies have identified family poverty as the major factor (Diggle et al., 2002; Onwujekwe et al., 2009; Ayele et al., 2013; Gayawan et al., 2014; Adebayo et al., 2016). These papers show that significant progress has been made in studying malaria epidemiology in Nigeria. However, evaluating the relationship between the geographical distribution of the disease and plausible risk factors across the nation remains largely unexplored, especially with regard to the under-5s. Our study therefore aimed to explore the influence of socioeconomic, demographic and geographical factors on childhood malaria prevalence that may aid future control and prevention efforts in Nigeria. Our second goal was to develop predicted risk maps for under-5 malar- ia in order to identify areas that should be targeted for effective public health resource allocation and intervention strategies, which is essential for the WHO Global Technical Strategy for Malaria 2016-2030 (WHO, 2019).

\section{Materials and methods}

\section{The study data}

The analysis in this paper is based on data available from the second and the most recent NMIS (2015) on malaria prevalence among children aged under 5 years in Nigeria. The survey was commissioned by the National Malaria Control Programme and implemented by the National Population Commission (NPC) together with donor agencies like Roll Back Malaria (RBM) partners. The sampling frame for the 2015 NMIS was the 2006 National Population and Housing Census (NPHC) of the Federal Republic of Nigeria, of which a total population of 140,431,790 people was recorded (NMC, 2015).

A two-stage probability sampling strategy was implemented for the data collection. At the first stage, 9 cluster Enumeration Areas (EAs) were selected from each stratum (NMC, 2015). The sample represented each state in Nigeria and the result of the sample included a total of 333 clusters across the country, 138 urban clusters and 195 clusters in rural areas. In the second stage, an equal probability sampling was adopted, where 25 houses were selected in each of the clusters. All women aged 15-49 years in each household were interviewed and, in addition, all children aged 6-59 months from the selected households were tested for malaria and anaemia via blood samples (NMC, 2015).

Moreover, the surveyed clusters were subsequently georeferenced with specific data files on geographic locations of the clusters and Global Positioning System (GPS) coordinates were recorded for the approximate centre of each of the primary sampling units (NDHS, 2016). To ensure each respondent's confidentiality, the geographical locations were randomly displaced at $2 \mathrm{~km}$ for urban clusters and up to $10 \mathrm{~km}$ for rural clusters as seen in Figures 1 and 2. The figures show the survey locations across Nigeria's 37 states, including the Federal Capital Territory (FCT) of Abuja. More details on the 2015 NMI survey may be obtained via the MEASURE DHS website (NDHS, 2016). Note that some parts of Borno State in the north-eastern region of Nigeria were not covered by the 2015 NMIS due to security concerns and therefore not included in the analysis (NMC, 2015).

\section{The response variable}

In controlling the risk of malaria and reducing the high mortality rate in endemic regions, the WHO recommends timely diagnosis and instant treatment as key strategies; hence, both microscopy and Rapid Diagnostic Tests (RDTs) are approved for malaria diagnosis in field surveys (WHO, 2015), as they were in the 2015 NMIS. Though the RDT has been mostly utilized during population surveys due to reliability, lower expense and speedy approach for early detection of the malaria parasite in human blood. In this study, the outcome of interest was based on malaria RDT survey results as a binary indicator of the presence of malaria parasites in the child's blood sample, where 1 signifies the presence of malaria and 0 the opposite. A total of 6,070 eligible children between ages 6 and 59 months that participated in the 2015 NMI survey were included in the analysis. 


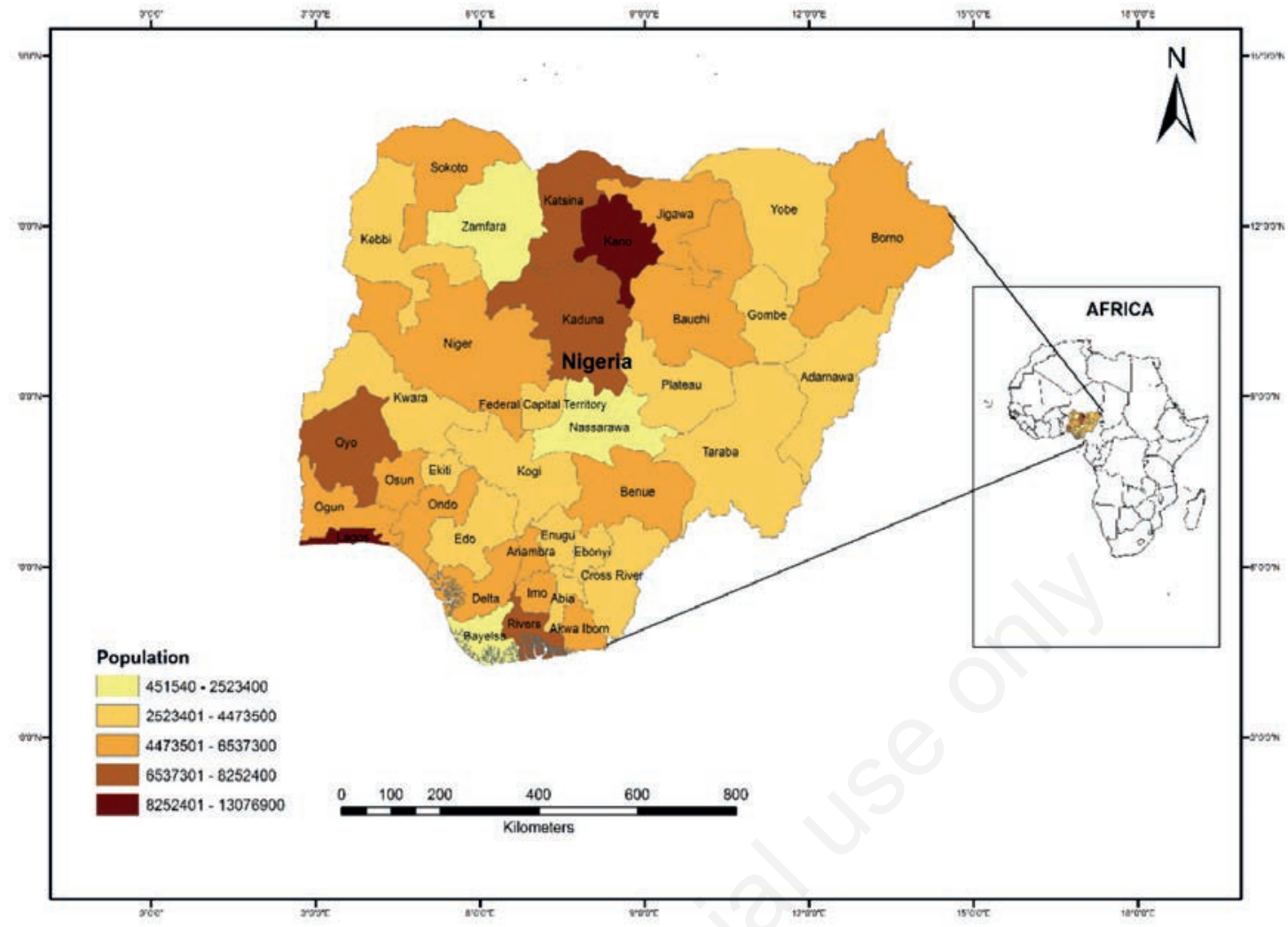

Figure 1. Map of Nigeria (the study area) based on the 2006 population census, indicating 333 clusters (37 states, including the Federal Capital Territory (FCT) under the 6 geopolitical regions).

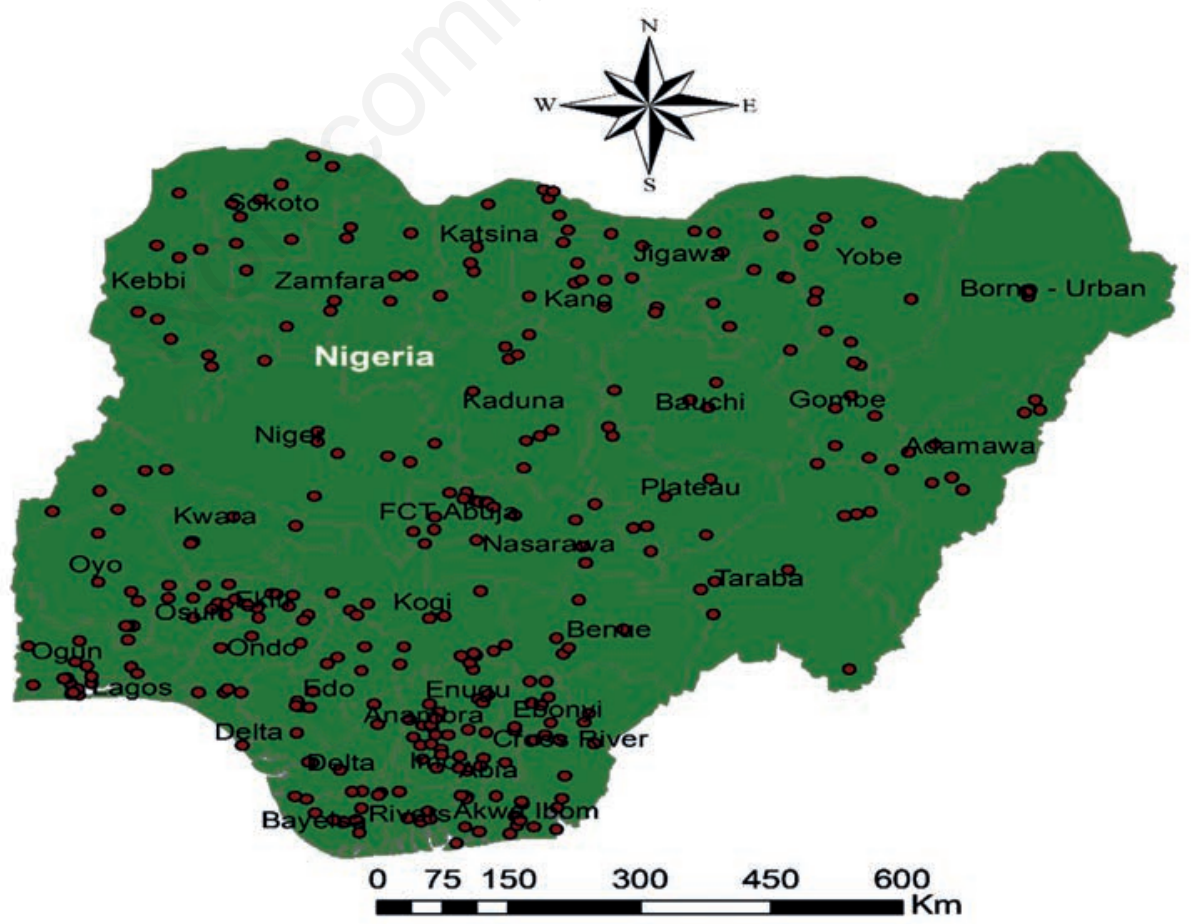

Figure 2. Map of Nigeria showing surveyed locations of under-5 malaria prevalence including the 7,745 households selected from 333 clusters randomly displaced $2 \mathrm{~km}$ for urban clusters and $10 \mathrm{~km}$ for rural clusters for confidentiality reasons. 


\section{The explanatory variables}

The explanatory variables were the selected baseline socioeconomic, demographic and geographic variables obtained at the household and individual levels from the 2015 NMIS. These variables were selected after a comprehensive literature review (Diggle et al., 2002; Gayawan et al., 2014; Samadoulougou et al., 2014; Adigun et al., 2015; Adebayo et al., 2016). However, the household wealth index, which is described as an indicator of the household's economic status categorized as (poorest, poorer, middle-range, richer and richest) were generated using Principal Component Analysis (PCA) from NMIS. The PCA value is estimated based on household's ownership of consumer goods, household dwelling characteristics, source of drinking water, sanitation facilities such as type of toilet facilities in the household, material for household construction and other factors related to individual household's socioeconomic status. Therefore, the variables above were not included independently in the present analysis, but predictor variables previously identified as influential factors in malaria disease risk from prior studies were. They included sex, age in months, anaemic status, mother's educational level, age and sex of the head of the household, type of place of residence, household wealth index, use of mosquito indoor residual spray in the past twelve months, use of Long-Lasting Insecticidal Nets (LLINs) during sleep and number of household members. Moreover, the states and regions were considered as the geographic variables linked with the Cartesian coordinates (longitude \& latitude) and employed as spatial random components for the purpose of locating the malaria observations in space as seen in the variable descriptions (Table 1).

\section{Statistical modelling}

Many epidemiological datasets are non-Gaussian, with spatially correlated observations. A critical assumption of various statistical modelling methods is independence of observations (Nelder and Wedderburn, 1972). However, in the case of spatially correlated data, the assumption of independence is usually unrealistic for standard regression models, i.e. spatially correlated observations fail to satisfy the critical assumption of independence central to such models due to the fact that observations in each geographical unit usually depends on the outcome in the neighbouring units, since proximate observations are correlated in space (Stroup, 2012). If a standard regression model fits such spatial data, the model residuals are without doubt independent among the observational units, and as such the critical assumption of the independence is violated resulting in unbiased estimates and invalid inferential conclusions (Stroup, 2012). For the geo-referenced data obtained for this study, a logistic regression model as a special case of the Generalized Linear Mixed Models (GLMMs) that include all variables of interest generated spatially auto-correlated residuals (Moran's $I=0.233, \mathrm{P}<0.0001$ ), (Cressie, 1992). The outcomes of Moran's $I$ calculations provide a strong indication whether or not spatial autocorrelation needs to be accounted for. Therefore, the GLMM framework, which combines the Generalized Linear Models (GLMs) with the Linear Mixed Models (LMMs), (Laird and Ware, 1982; Nelder and Wedderburn, 1972; McCulloch and Searle, 2001), present a model that allows spatial random effects in addition to usual fixed effects in modelling non-Gaussian malaria prevalence data with correlations. Here, we employed the GLMM framework to fit the under-5 malaria prevalence data using the logit link function as follows:

$$
g(\mu)=\log (\mu / 1-\mu)
$$

unlike standard regression models, GLMM inference accounts for spatial correlation (McCulloch and Searle, 2001; Nelder and Wedderburn, 1972; Stroup, 2012). The GLMM which allows the integration of the spatial correlation model through the G-side covariance structure of the GLMM is given as:

$$
\mu=E(Y \mid U=u)=\phi\left(X^{\prime} \beta+\varphi^{\prime} u\right)
$$

where $\beta$ is a dimensional vector of fixed-effect parameters, the dimensional vector of covariates and $\phi()=.\mathrm{g}^{-1}($.$) the inverse link$ function. Specifically, we obtained a suitable spherical spatial covariance structure:

$$
\delta^{2}\left[1-\left(\frac{3 d_{i j}}{2 \rho}\right)+\left(\frac{d_{i j}^{3}}{2 \rho^{3}}\right)\right] 1\left(\rho d_{i j} \leq \rho\right)
$$

via the PROC variograms procedure that adequately accounted for the spatial variability in our data as specified below.

Table 1. Socioeconomic, geographic and demographic variables analyzed for association with under-5 malaria prevalence in Nigeria.

\begin{tabular}{ll}
\hline Factor & Description \\
$\begin{array}{l}\text { Region } \\
\text { Residence }\end{array}$ & North central, North-east, North-west, South-east, South, South-west \\
\hline Anaemia & Dichotomous variable: rural* or urban \\
Child slept under LLIN* & Dichotomous variable: yes or no* \\
\hline Household sprayed & Dichotomous variable: yes or no* \\
Child's sex & Dichotomous variable: yes or no* \\
\hline Sex of household-head & Dichotomous variable: yes or no* \\
Child's age in months & Continuous variable: minimum=6, maximum $=59$ \\
\hline Age of household-head & Continuous variable: minimum $=15$, maximum $=98$ \\
Family size & Continuous variable: minimum=2, maximum=1344 \\
\hline Mother's educational level & Categorical variable: no education*, primary, secondary, higher education \\
Household wealth index & Categorical variable: poorest*, poorer, middle-range, richest, richer
\end{tabular}

${ }^{*}$ Long-lasting insecticidal net; ${ }^{*}$ Reference variable (see Table 4). 
Let $y_{i j}$ denote the binary response corresponding to the $j^{\text {th }}$ child's malaria outcome at the spatial location $S_{i}, i=1, \ldots \ldots,-i$ take values of 1 for positive malaria outcome and 0 otherwise. Let $x_{i j}$ represent the vector of associated covariates observed at the spatial location $S_{i}$. Within the GLMM framework, we assume that the response variable, $y_{i j}$, has a probability of belonging to the exponential family. Considering $S_{i}$ to be a spatial location within the geographical domain $D$, we defined the fundamental geostatistical tool as follows:

$$
\phi(d)=1 / 2 E\left[y_{i j}\left(s_{i}\right)-y_{i j}\left(s_{-i}\right)\right]^{2}
$$

where $\phi(d)$ denotes the semi-variogram, $d$ a spatial distance, $s_{i}$ and $s_{-i}$ two spatial locations with $d$-distance apart and $y_{i j}\left(s_{i}\right) \& y_{i j}\left(s_{-i}\right)$ the under-5 malaria observations at the spatial locations $s_{i}$ and $s_{-i}$, respectively. We take account of the spatial dependency of the data by integrating an appropriate spatial covariance model obtained via the semi-variogram model into the G-side covariance structure of the GLMM (Gotway and Stroup, 1997; Stroup, 2012). This was achieved by assuming that the response variable $y_{i j}$, conditioned on the realization of a random effect vector $u_{i}$, is conditionally independent for any spatial location $S_{i}$ with conditional expectation:

$$
E\left[y_{i j}\left(S_{i}\right) \mid u_{i}\right]=\pi_{i j}\left(S_{i}\right)
$$

Thus, the linear predictor which includes the spatially correlated random effect can be represented as Spatially Generalized Linear Mixed Models (S-GLMM) in the form of

$$
g\left(\pi_{i j}\right)=\eta_{i j}=X_{i j} \beta+Z_{i j} u_{i}\left(S_{i}\right)
$$

where, the random term $u_{i}$ defines the spatial distribution of the malaria observation, $u_{i} \sim N\left(0, \Sigma_{u}\right)$ with the spatial spherical function

\begin{tabular}{|c|c|c|c|}
\hline Characteristic & Category & No. & $\%$ \\
\hline Geographical region & $\begin{array}{l}\text { North central } \\
\text { North-east } \\
\text { North-west } \\
\text { South-east } \\
\text { South } \\
\text { South-west }\end{array}$ & $\begin{array}{c}1,138 \\
826 \\
1,958 \\
577 \\
672 \\
959\end{array}$ & $\begin{array}{r}18.7 \\
13.6 \\
32.3 \\
8.5 \\
11.1 \\
15.8\end{array}$ \\
\hline Type of place of residence & $\begin{array}{l}\text { Rural } \\
\text { Urban }\end{array}$ & $\begin{array}{l}4,033 \\
2,037\end{array}$ & $\begin{array}{l}66.4 \\
33.6\end{array}$ \\
\hline Child's sex & Male & 3,079 & 50.7 \\
\hline Child's age in months & $\begin{array}{l}\text { 6-24 months } \\
13-24 \text { months } \\
25-36 \text { months } \\
37-48 \text { months } \\
\text { 49-59 months }\end{array}$ & \begin{tabular}{c|}
721 \\
1,283 \\
1,309 \\
1,417 \\
1,341
\end{tabular} & $\begin{array}{l}11.9 \\
21.1 \\
21.6 \\
23.3 \\
22.1\end{array}$ \\
\hline Anaemia & $\begin{array}{l}\text { No } \\
\text { Yes }\end{array}$ & $\begin{array}{l}1,917 \\
4,150\end{array}$ & $\begin{array}{l}31.6 \\
68.4\end{array}$ \\
\hline Mother's educational level & $\begin{array}{l}\text { No education } \\
\text { Primary } \\
\text { Secondary } \\
\text { Higher }\end{array}$ & $\begin{array}{c}2,423 \\
948 \\
1,568 \\
412\end{array}$ & $\begin{array}{r}39.9 \\
15.6 \\
25.8 \\
6.8\end{array}$ \\
\hline Household wealth index & $\begin{array}{l}\text { Poorest } \\
\text { Poorer } \\
\text { Middle-range } \\
\text { Richer } \\
\text { Richest }\end{array}$ & $\begin{array}{l}1,244 \\
1,407 \\
1,175 \\
1,115 \\
1,129\end{array}$ & $\begin{array}{l}20.5 \\
23.2 \\
19.4 \\
18.4 \\
18.6\end{array}$ \\
\hline Child slept under LLIN* & $\begin{array}{l}\text { No } \\
\text { Yes }\end{array}$ & $\begin{array}{l}3,457 \\
2,613\end{array}$ & $\begin{array}{l}57 \\
43\end{array}$ \\
\hline Result of malaria RDT** & $\begin{array}{l}\text { Negative } \\
\text { Positive }\end{array}$ & $\begin{array}{l}3,334 \\
2,736\end{array}$ & $\begin{array}{l}54.9 \\
45.1\end{array}$ \\
\hline
\end{tabular}

Table 2. Socio-demographic characteristics of under-5 malaria prevalence in Nigeria based on 2015- NMIS.

*Long-lasting insecticidal net; **Rapid diagnostic test.

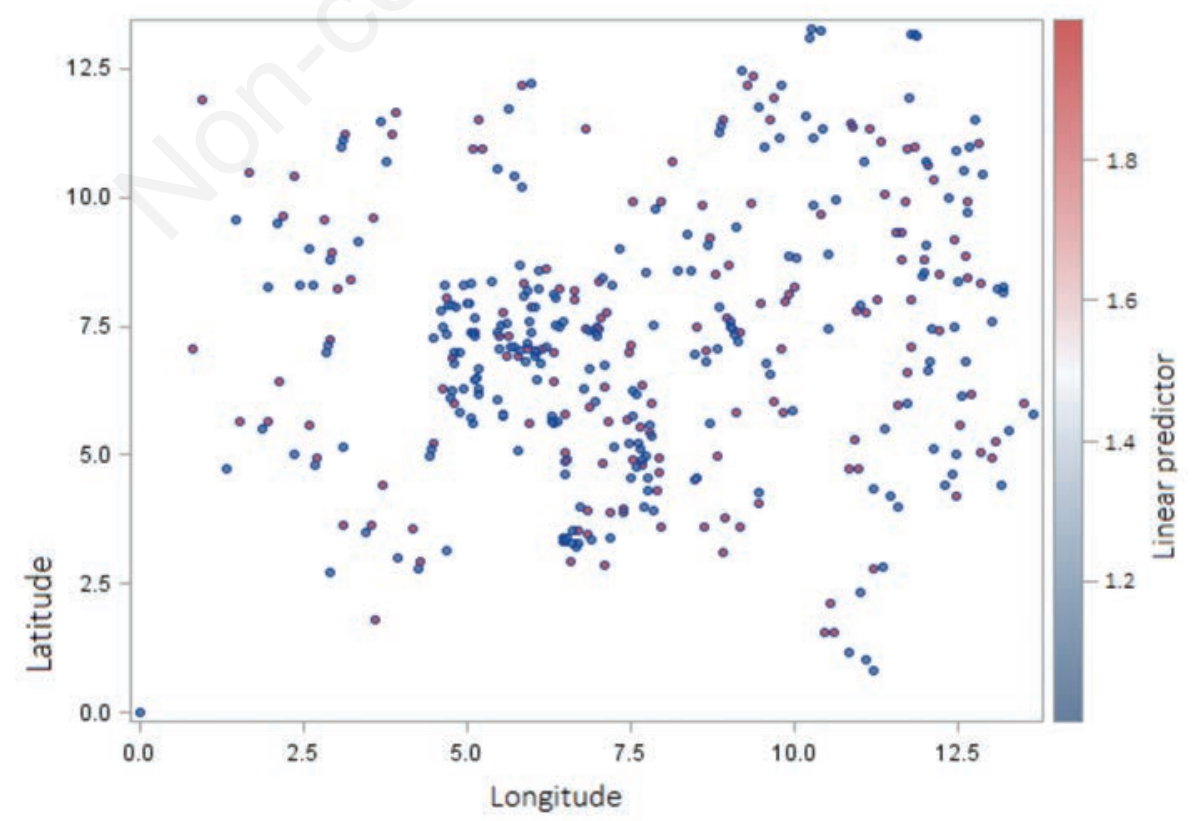

Figure 3. Scatter plot of under-5 malaria prevalence. Blue dots represent negative malaria test outcomes and red dots represent positive outcomes. 
of the distances specified by two geographic coordinates (longitude and latitude) and $g($.) the link function that relates the binary response to the linear predictors.

The predicted values from the model were mapped to obtain risk maps for the under-5 malaria infections at the national level. This was achieved by generating the fitted values of the response variable predicted by the S-GLMM fitted to the data, on which we applied ordinary Kriging to infer values at unobserved locations in the proximity of the data points; hence, a spherical semi-variogram model obtained via the Proc Variogram procedure was found suitable for the Kriging (Cressie, 1992). This approach enabled us to model and map the risk of under-5 malaria to identify critical hotspots of malaria clusters. The spatial analysis was carried out using ArcGIS, version 10.6.1 (ESRI, Redlands, CA, USA) and the statistical analysis was implemented using SAS statistical software, version 9.4 (SAS Institute Inc., Cary, NC, USA). The significance level in our analysis was $\mathrm{P}=0.05$.

\section{Results}

Table 2 presents the sociodemographic characteristics of children and household variables included in the study. A total of 6,070 children aged 6 to 59 months who were tested for malaria by RDT was included in this study. The mean $( \pm \mathrm{SD})$ age of children was $4.2( \pm 1.5)$ months, the majority of whom were males $(3,079$ $50.7 \%)$. The number of female children was 2,999 (49.3\%). Regarding age, there were 721 children between 6-12 months (11.9\%), 1,283 between 13-24 months (21.1\%), 1,309 between 25 36 months $(21.6 \%), 1,417$ between $37-48$ months $(23.3 \%)$ and 1,341 between $49-59$ months (22.1\%). Most of these children lived in rural areas $4,033(66.4 \%)$ with only a small number of them in urban areas 2,037 (33.6\%). The number of under-5s with illiterate mothers was proportionally greater $2,423(39.9 \%)$ as compared to mothers with primary education: 948 (15.6\%), secondary education: 1,568 (25.8\%) and higher-level education: $412(6.8 \%)$. According to the household socioeconomic status, 1,244 (20.5\%) of the children resided in the poorest households, while 1,407 (23.2\%), 1,175 (19.4\%), 1,115 (18.4\%) and 1,129 (18.6) of them resided in the poorer, middle-range, richer and richest households, respectively. Furthermore, malaria infection was observed in 2,736 (45.1\%) of the under-5s and the percentage of the children who slept under LLINs prior to the survey was 2,613 (43.0\%).

Table 3 presents the goodness-of-fit results of three spatial covariance structures investigated, including the exponential spatial covariance structure SP (EXP), the Gaussian spatial covariance structure SP (GAU) and the spherical spatial covariance structure SP (SPH), (Kincaid, 2005). The spatial covariance estimates via the empirical semi-variogram model were computed using the PROC VARIOGRAM procedure in SAS (Kincaid, 2005). The results show that the SP (SPH) had the smallest Akaike Information Criterion (AIC), the smallest Akaike Information Criterion Corrected (AICC), the smallest Bayesian Information Criterion (BIC) and the smallest Res Log Likelihood, and that it thus fitted the data best. SP (SPH) was subsequently employed in our analysis (Zimmerman and Harville, 1991; Kincaid, 2005; Stroup, 2012). As shown in Table 3, the spatial random effect cluster, which characterizes the spatial variability, was significant. In the diagnosis of the residual of the S-GLMM, a random distribution was observed with no residual structure not accounted for by the model, thus indicating a good model fit to the data. Figure 3 presents the spatial scatter plot of the observed malaria data, providing values of measured variables in the form of different coloured markers for positive and negative outcomes. The plot suggests that the under-5 malaria cases were unevenly spread around the observed locations, with evidence that the spatial distribution of high values and low values with respect to malaria prevalence presented a more spatially clustered data. Thus, the distribution of malaria was not an indication of uniform distribution, rather, an indication of random spread of malaria outcome (Verly et al., 2013; Keranen and Kolvoord, 2017). Hotspots of under-5 malaria infection in Nigeria were localized predominantly in the North-west and North-east regions as seen in Figure 4. From the predicted risk map, it was observed that only the South-East region had a lower likelihood of under-5 malaria. Figure 5 presents the spatial variation of under- 5 malaria prevalence within the 36 states, including the Federal Capital Territory (FCT) of Abuja. The map

Table 3. Comparative fit statistics and covariance parameter estimates for the G-side spherical spatial model.

\begin{tabular}{lccc}
\hline Model-fit criteria & SP(SPH) & SP(EXP) & SP(GAU) \\
-2 Res Log Likelihood & $5,662.11$ & $5,668.90$ & $5,938.35$ \\
AIC $^{\mathrm{b}}$ & $5,776.11$ & $5,782.90$ & $6,052.35$ \\
\hline AICC $^{\mathrm{e}}$ & $5,777.39$ & $5,784.18$ & $6,053.62$ \\
BIC $^{\mathrm{f}}$ & $5,991.96$ & $5,998.75$ & $6,268.20$ \\
\hline Covariance parameter estimates for SP(SPH) $^{\mathrm{a}}$ & \\
\hline Effect & Estimate & SD & P-value \\
SP(SPH) & & & \\
\hline Variance & 2.7156 & 0.1368 & $<0.0001$ \\
\hline Residual & 0.1086 & 0.0175 & $<0.0001$ \\
\hline
\end{tabular}

${ }^{a}$ spherical spatial covariance structure; bexponential spatial covariance structure; cGaussian spatia

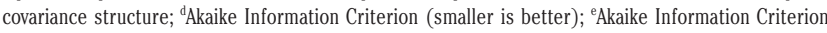
Corrected (smaller is better); 'Bayesian Information Criterion (smaller is better).

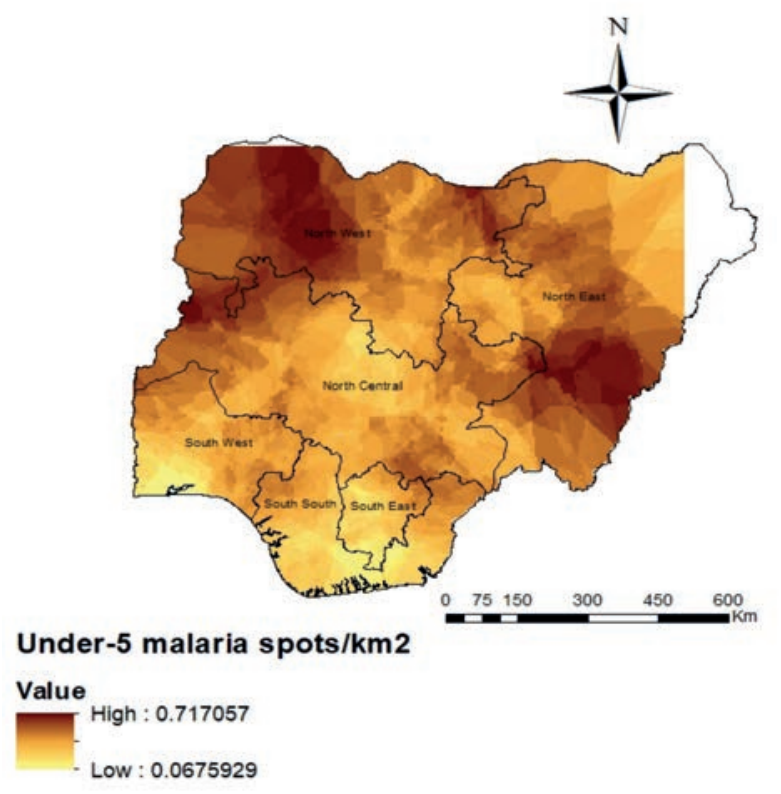

Figure 4. Risk map of under-5 malaria infection as predicted by the spatial generalized linear mixed model for the 6 geopolitical regions of Nigeria. The colorimetric scale represents the number of infected under- 5 children per $\mathbf{k m}^{2}$. 
indicated the states Zamfara, Sokoto, Kebbi, Adamawa, Gombe and Jigawa as having the highest risk of under-5 malaria prevalence, followed by Benue, Niger, Kwara, Kano and Plateau. The risk was lowest in the staes Rivers, Akwa-Ibom, Anambra, Enugu and Ogun, which are mostly in the Southern regions.

Table 4 presents summarized estimates of $\beta$-coefficients, oddratios, the corresponding 95\% confidence intervals and $\mathrm{P}$-values estimated by the GLMMs with and without spatial correlation. When the spatial effect was ignored, the estimated fixed effects were inflated by about threefold (over-estimation) as seen in Table 4. Our results show that an over-estimated output would be obtained if the spatial effect was not accounted for in the GLMM. However, the findings of the two models varied slightly, except for the estimated LLIN effect. The availability and usage of LLINs among the under5 group acted as significant protective factors for malaria infection, only after adjusting for spatial correlation. The result implies that non-availability and non-usage of LLINs are risk factors with respect to under-5 malaria $\mathrm{P}=0.0373,0.0427$ ). The low Household Socio-Economic Factor (HSEF) revealed a strong statistical association with under-5 malaria and was consistent after adjusting for the spatial effects $(\mathrm{P}=<0.0001)$. The household wealth index (poorest, poorer and middle-range) showed a positive association with malaria regardless of adjusting for spatial correlation. The presence of anaemia in children revealed a statistically significant positive association with malaria infection, regardless of spatial effects and after adjusting for spatial location $(\mathrm{P}=<0.0001)$. Several variables appeared to be risk factors for under-5 malaria, regardless of accounting for the spatial effects. They are the type of place of residence, poverty of the household, low mother's educational attainment, family size, age of the child and the head of household.

Table 4. Associations between under-5 malaria prevalence and baseline socioeconomic, demographic and geographic factors.

\begin{tabular}{|c|c|c|c|c|c|c|c|c|c|c|}
\hline \multirow[b]{2}{*}{ Variable } & \multicolumn{5}{|c|}{ Nonspatial-GLMM } & \multicolumn{4}{|c|}{ Spatial-GLMM } & \multirow[b]{2}{*}{ P-value } \\
\hline & Mean & SD & OR & $95 \%$ CL & P-value & Mean & SD & OR & $95 \%$ CL & \\
\hline Intercept & -4.2937 & 0.5687 & 0.0137 & 0.00450 .042 & $<.0001$ & -0.1614 & 0.1237 & 0.8511 & 0.66771 .0844 & 0.1931 \\
\hline $\begin{array}{l}\text { Region (Ref. North West) } \\
\text { South East } \\
\text { South South } \\
\text { South West } \\
\text { North Central } \\
\text { North East } \\
\end{array}$ & $\begin{array}{l}0.3081 \\
-0.4598 \\
0.2795 \\
-0.3401 \\
-1.2204 \\
\end{array}$ & $\begin{array}{l}0.3786 \\
0.4612 \\
0.3599 \\
0.4435 \\
0.4895\end{array}$ & $\begin{array}{l}1.3608 \\
0.6314 \\
1.3225 \\
0.7117 \\
0.2951\end{array}$ & $\begin{array}{l}0.64792 .8580 \\
0.25571 .5591 \\
0.6532 \\
0.6776 \\
0.29831 .6975 \\
0.11310 .7703\end{array}$ & $\begin{array}{l}0.4163 \\
0.3196 \\
0.4381 \\
0.4438 \\
0.0132\end{array}$ & $\begin{array}{l}-0.0499 \\
-0.0651 \\
-0.0538 \\
-0.1901 \\
-0.1088 \\
\end{array}$ & $\begin{array}{l}0.1278 \\
0.1346 \\
0.1393 \\
0.0937 \\
0.1111\end{array}$ & $\begin{array}{l}0.9513 \\
0.9371 \\
0.9476 \\
0.8269 \\
0.8969\end{array}$ & $\begin{array}{l}0.74051 .2221 \\
0.71971 .2198 \\
0.72121 .2451 \\
0.68810 .9936 \\
0.72151 .1151 \\
\end{array}$ & $\begin{array}{l}0.6965 \\
0.6285 \\
0.6992 \\
0.0427 \\
0.3269\end{array}$ \\
\hline $\begin{array}{l}\text { Place of residence (Ref. Urban) } \\
\text { Rural }\end{array}$ & 1.4641 & 0.4575 & 4.3236 & 1.763710 .5994 & 0.0015 & 0.2948 & 0.0721 & 1.3429 & 1.16591 .5467 & $<.0001$ \\
\hline $\begin{array}{l}\text { Wealth index (Ref. Richest) } \\
\text { Poorest } \\
\text { Poorer } \\
\text { Middle-range } \\
\text { Richer }\end{array}$ & $\begin{array}{l}1.3989 \\
1.9532 \\
1.1308 \\
0.6536\end{array}$ & $\begin{array}{l}0.4114 \\
0.3503 \\
0.2445 \\
0.1832\end{array}$ & $\begin{array}{l}4.0507 \\
7.0512 \\
3.0981 \\
1.9224\end{array}$ & $\begin{array}{c}1.80869 .0723 \\
3.548914 .0102 \\
1.91865 .0029 \\
1.34252 .7529\end{array}$ & $\begin{array}{l}<.0001 \\
<.0001 \\
<.0001 \\
0.0007\end{array}$ & $\begin{array}{l}0.2226 \\
0.2973 \\
0.1621 \\
0.0596\end{array}$ & $\begin{array}{l}0.0731 \\
0.0593 \\
0.0401 \\
0.0269\end{array}$ & $\begin{array}{l}1.2536 \\
1.3462 \\
1.1759 \\
1.0614\end{array}$ & $\begin{array}{l}1.08261 .4418 \\
1.19851 .5121 \\
1.08711 .2721 \\
1.00691 .1189\end{array}$ & $\begin{array}{l}0.0023 \\
<.0001 \\
<.0001 \\
0.0273\end{array}$ \\
\hline $\begin{array}{l}\text { Mother's education (Ref. Higher) } \\
\text { No education } \\
\text { Primary } \\
\text { Secondary }\end{array}$ & $\begin{array}{l}0.6759 \\
0.4381 \\
0.4052\end{array}$ & $\begin{array}{l}0.2018 \\
0.1979 \\
0.1815\end{array}$ & $\begin{array}{l}1.9659 \\
1.5498 \\
1.4996\end{array}$ & $\begin{array}{l}1.32367 .3939 \\
0.65672 .2841 \\
1.05072 .1403\end{array}$ & $\begin{array}{l}0.0009 \\
0.0273 \\
0.0261\end{array}$ & $\begin{array}{l}0.0984 \\
0.0509 \\
0.0549\end{array}$ & $\begin{array}{l}0.0295 \\
0.0286 \\
0.0247\end{array}$ & $\begin{array}{l}1.1034 \\
1.0522 \\
1.0564\end{array}$ & $\begin{array}{l}1.04141 .3381 \\
1.11291 .1129 \\
1.11291 .1129\end{array}$ & $\begin{array}{l}0.0009 \\
0.0347 \\
0.0261\end{array}$ \\
\hline $\begin{array}{l}\text { Bed net (Ref. All used) } \\
\text { No bed-net } \\
\text { Some used } \\
\text { No child used }\end{array}$ & $\begin{array}{l}-0.1908 \\
-0.1747 \\
-0.1791\end{array}$ & $\begin{array}{l}0.1318 \\
0.1103 \\
0.1188\end{array}$ & $\begin{array}{l}0.8263 \\
0.8397 \\
0.8361\end{array}$ & $\begin{array}{l}0.63821 .0699 \\
0.67651 .0423 \\
0.66241 .0552\end{array}$ & $\begin{array}{l}0.1481 \\
0.1137 \\
0.1322\end{array}$ & $\begin{array}{c}0.0396 \\
-0.0299 \\
0.0272\end{array}$ & $\begin{array}{l}0.0224 \\
0.0192 \\
0.0204\end{array}$ & $\begin{array}{l}1.0404 \\
0.9705 \\
1.0276\end{array}$ & $\begin{array}{l}0.99571 .0871 \\
0.93471 .0078 \\
0.98731 .0695\end{array}$ & $\begin{array}{l}0.0373 \\
0.1187 \\
0.0427\end{array}$ \\
\hline $\begin{array}{l}\text { Spraying (Ref. Yes) } \\
\text { No }\end{array}$ & -0.1041 & 0.3492 & 0.9012 & 0.45451 .7866 & 0.7676 & -0.0168 & 0.0555 & 0.9833 & 0.88191 .0963 & 0.7624 \\
\hline $\begin{array}{l}\text { Child's age (Ref. 6-12 months) } \\
\text { 13-24 months } \\
\text { 25-36 months } \\
37-48 \text { months } \\
\text { 49-59 months }\end{array}$ & $\begin{array}{l}0.5316 \\
0.9618 \\
1.2587 \\
1.5432\end{array}$ & $\begin{array}{l}0.1201 \\
0.1203 \\
0.1198 \\
0.1235\end{array}$ & $\begin{array}{l}1.7017 \\
2.6164 \\
3.5208 \\
4.6795\end{array}$ & $\begin{array}{l}1.68342 .1533 \\
2.06683 .3121 \\
2.78404 .4527 \\
3.67355 .9611\end{array}$ & $\begin{array}{l}<.0001 \\
<.0001 \\
<.0001 \\
<.0001\end{array}$ & $\begin{array}{l}0.0865 \\
0.1567 \\
0.2074 \\
0.2554\end{array}$ & $\begin{array}{l}0.0199 \\
0.0201 \\
0.0198 \\
0.0203\end{array}$ & $\begin{array}{l}1.0904 \\
1.1696 \\
1.2305 \\
1.2909\end{array}$ & $\begin{array}{l}1.04861 .1337 \\
1.12451 .2166 \\
1.18361 .8476 \\
1.24061 .3433\end{array}$ & $\begin{array}{l}<.0001 \\
<.0001 \\
<.0001 \\
<.0001\end{array}$ \\
\hline $\begin{array}{l}\text { Child's sex (Ref. Male) } \\
\text { Female }\end{array}$ & -0.0585 & 0.0661 & 0.9432 & 0.82861 .0736 & 0.3777 & -0.0112 & 0.0113 & 0.9889 & 0.96721 .0111 & 0.3211 \\
\hline $\begin{array}{l}\text { Anaemic status (Ref. No) } \\
\text { Yes } \\
\text { Age of head of household } \\
\text { Family size }\end{array}$ & $\begin{array}{l}1.1072 \\
0.0132 \\
0.0671\end{array}$ & $\begin{array}{l}0.0791 \\
0.0055 \\
0.0329\end{array}$ & $\begin{array}{l}3.0259 \\
1.0133 \\
1.0694\end{array}$ & $\begin{array}{l}2.59133 .5333 \\
1.00241 .0243 \\
1.00261 .1406\end{array}$ & $\begin{array}{l}<.0001 \\
0.0161 \\
0.0421\end{array}$ & $\begin{array}{l}0.1871 \\
0.0023 \\
0.0111\end{array}$ & $\begin{array}{l}0.0132 \\
0.0009 \\
0.0055\end{array}$ & $\begin{array}{l}1.2057 \\
1.0023 \\
1.0116\end{array}$ & $\begin{array}{l}1.17501 .2374 \\
1.00051 .0041 \\
1.00031 .0221\end{array}$ & $\begin{array}{l}<.0001 \\
0.0108 \\
0.0443\end{array}$ \\
\hline Number of rooms & -0.0199 & 0.0251 & 0.9803 & 0.93321 .0297 & 0.4257 & -0.0024 & 0.0045 & 0.9976 & 0.98881 .0064 & 0.5961 \\
\hline
\end{tabular}




\section{Discussion}

The study investigated important associations between different socioeconomic, demographic and geographic factors and under-5 malaria prevalence in Nigeria. Risk maps of this prevalence were developed based on the available data, to also identify high-risk regions. We observed that the geographical inequalities in health are strongly associated with the socioeconomic conditions and inefficient public health resource allocations as pointed out by Onwujekwe et al. (2009). The results show that, the unavailability and non-usage of LLINs among the under-5 part of the population increased the likelihood of malaria infections. It is evident from the results that households where all children or some children had slept under LLINs prior to the survey reduced the risk of malaria as compared to those households without LLINs. These results are in line with previous findings, that the use of LLINs reduces malaria infection (Ayele et al., 2013; Samadoulougou et al., 2014; Yaya et al., 2018). However, whether dwelling has been sprayed against mosquitoes or not in the last 12 months prior to the survey was insignificant in this study. We found that under-5 malaria infections were more common among children living in low-income households, thus supporting the view that low socioeconomic factors such as poverty influences the vulnerability of under-5s to malaria infection (Diggle et al., 2002; Onwujekwe et al., 2009; Adigun et al., 2015; Adebayo et al., 2016; Samadoulougou et al., 2014).

Children living in rural areas in poor households constitute the vulnerable group, whose needs should be adequately weighed in future intervention policies, as they were found to be highly affected by malaria, which might be as a result of inaccessibility of health facilities and LLINs in the remote rural areas. In concurrence with the findings of Onwujekwe et al. (2009), Ayele et al. (2013), Samadoulougou et al. (2014) and Adebayo et al. (2016),

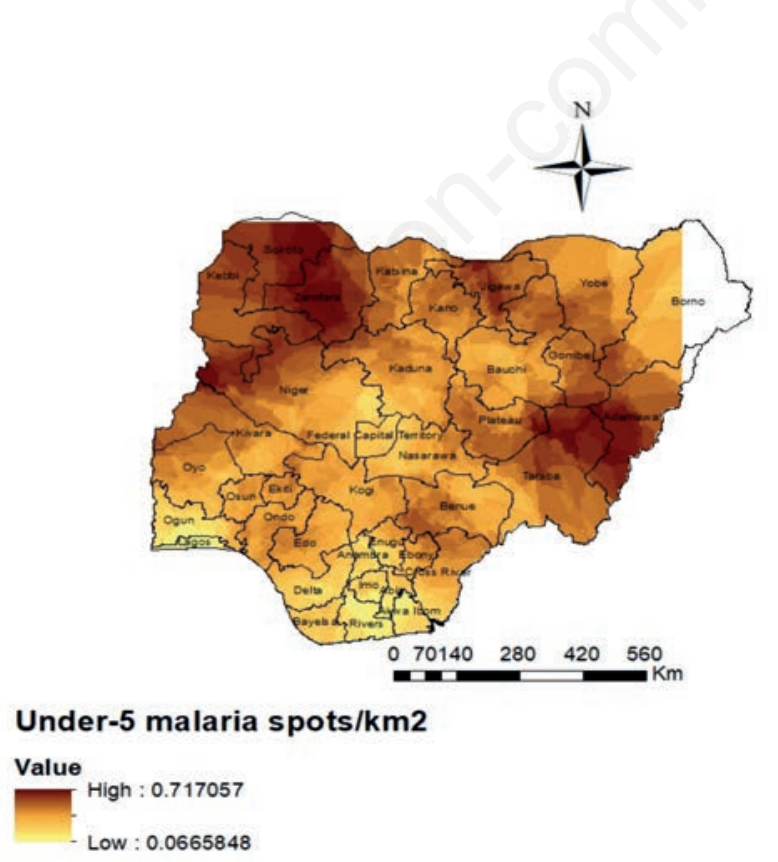

Figure 5. Risk map of under-5 malaria infection as predicted by the spatial generalized linear mixed model for the 36 states including the Federal Capital Territory of Nigeria. The colorimetric scale represents the number of infected under- 5 children per $\mathrm{km}^{2}$. children residing among what was called richer and richest households and those in families in urban areas were significantly less prone to malaria infection than their counterparts. According to Onwujekwe et al. (2009) and Okeke and Okeibunor (2010), children living in the rural areas show a higher rate of mortality than those living in urban areas, and this may last until the child reaches about 10 years of age. The analysis of socioeconomic factors shows that a low education of the mother is associated with under5 malaria (Kreuels et al., 2008; Ayele et al., 2013; Njau et al., 2014). In concurrence, our study found that the higher the level of the mother's education the more significantly negative is the correlation with under-5 malaria. The result implies that, an educated mother s likely to have the adequate knowledge required for malaria prevention, control and total care of her children. Moreover, the likelihood of an under-5 malaria infection vulnerability increased with age as observed from our results, with lower likelihood among children less than 25 months (Diggle et al., 2002; Ayele et al., 2013; Gayawan et al., 2014; Adebayo et al., 2016;). This can be attributed to the fact that children $<20$ months old are protected through maternal immunity (Adebayo et al., 2016). The age of the household head is known to influence malaria among children, with malaria infection being significantly more common among children living with heads of households 60 years old and above (Ayele et al., 2013; Gayawan et al., 2014; Adebayo et al., 2016). Regarding the anaemia status, there is a strong statistically significant association between anaemia and malaria prevalence among under-5s. The positive malaria outcome was higher among the anaemic children than the non-anaemic children as they are seen to be highly inter-correlated (Yusuf et al., 2010). Therefore, malaria preventive measures can also protect the anaemic children, since both diseases share a common influence.

The identification of hotspots, which may reflect malaria eradication-limiting factors will allow the focusing of public health resource allocation to areas that have particularly high malaria burdens. Indeed, some areas in Nigeria show particularly high burdens of under-5 malaria, including hotspots. Our results suggest that the distribution of malaria is geographically structured and there are factors that influence certain areas to be more vulnerable than others. For instance, a strong correlation was observed between under5 malaria prevalence and areas where problem of poor socioeconomic conditions and rural population are predominant (Onwujekwe et al., 2009; Adigun et al., 2015). Indeed, other studies show that gaining a better understanding of the socioeconomic factors that favour malaria infection can raise the profile of malaria control management in both rural and urban areas through spatial analysis (Diggle et al., 2002; Ayele et al., 2013; Kazembe and Mathanga, 2016; Adebayo et al., 2016; Kreuels et al., 2008).

The following limitations should be considered when interpreting the results of this study: i) The study utilized a cross-sectional data from the 2015 NMIS, which lacks the capacity to make any casual inference; ii) the study did not examine other important factors such as: the entomology-vector variables, the vector breedingsites, climatic factors, environmental factors and geographic covariates, such as forest cover. The limitations may lead to insufficient analytical conclusions. However, despite these limitations, the study has identified potential other risk factors based on the available variables extracted from the 2015 NMIS database and has filled a gap in the spatial analysis of under-5 malaria prevalence in Nigeria based on GLMMs. 


\section{Conclusions}

The results presented provide important insight for public health practitioners working towards malaria eradication in Nigeria, which should specifically target children between ages 37-59 months residing with illiterate-poor mothers in the rural households across the identified high-risk regions of Nigeria. Under-5 malaria predictive risk maps show a clear spatial heterogeneity, which to an extent may be explained by variations in socioeconomic factors. The odds of malaria among the under- $5 \mathrm{~s}$ increase with family poverty, non-availability and non-usage of LLINs, low education of the mother, family size, age of the child, presence of anaemia and increased age of the head of household. Children in the rural areas were more at the risk of malaria than their urban counterparts, indicating a rural disadvantage in terms of malaria control and intervention. This need to be addressed under public health education and intervention programmes at the community or state level.

\section{References}

Adebayo SB, Gayawan E, Heumann C, Seiler C, 2016. Joint modeling of Anaemia and Malaria in children under five in Nigeria. Spat Spatiotemporal Epidemiol 17:105-15. doi:10.1016/j.sste. 2016.04.011

Adigun AB, Gajere EN, Oresanya O, Vounatsou P, 2015. Malaria risk in Nigeria: Bayesian geostatistical modelling of 2010 malaria indicator survey data. Malaria J 14:156. doi:10.1186/s 12936-015-0683-6

Akpan GE, Adepoju KA, Oladosu OR, 2019. Potential distribution of dominant malaria vector species in tropical region under climate change scenarios. PloS one, 2019. 14:e0218523. doi:10.1371/journal.pone.0218523

Awolola TS, Oduola AO, Obansa JB, Chukwurar NJ, Unyimadu JP, 2007. Anopheles gambiae ss breeding in polluted water bodies in urban Lagos, southwestern Nigeria. J Vector Borne Dis $44: 241$.

Ayele DG, Zewotir TT, Mwambi HG, 2013. Spatial distribution of malaria problem in three regions of Ethiopia. Malaria J 12:207.

Cressie N, 1992. Statistics for spatial data. Terra Nova 4:613-17. doi:10.1111/j.1365-3121.1992.tb00605.x

Diggle P, Moyeed R, Rowlingson B, Thomson M, 2002. Childhood malaria in the Gambia: a case-study in model-based geostatistics. J R Stat Soc C-Appl 51:493-506. doi:10.1111/ 1467-9876.00283

Ebenezer A, Noutcha AEM, Agi PI, Okiwelu SN, Commander T, 2014. Spatial distribution of the sibling species of A nopheles gambiae sensu lato (Diptera: Culicidae) and malaria prevalence in Bayelsa State, Nigeria. Parasit Vectors 7:32. doi:10.1186/1756-3305-7-32

Efe SI, Ojoh CO, 2013. Spatial distribution of malaria in Warri metropolis. Open J Epidemiol 3:118. doi:10.4236/ojepi. 2013.33018

Ferrao J, Niquisse S, Mendes J, Painho M, 2018. Mapping and modelling malaria risk areas using climate, socio-demographic and clinical variables in Chimoio, Mozambique. Int J Environ Res Public Health 15:795. doi:10.3390/ijerph15040795

Gayawan E, Arogundade ED, Adebayo SB, 2014. A Bayesian multinomial modeling of spatial pattern of co-morbidity of malaria and non-malarial febrile illness among young children in Nigeria. Trans R Soc Trop Med Hyg 108:415-24. doi: $10.1093 / \mathrm{trstmh} / \mathrm{tru} 068$

Gotway CA, Stroup WW, 1997. A generalized linear model approach to spatial data analysis and prediction. J Agr Biol Envir Stat 157-78. doi:10.2307/1400401

Idowu AP, Okoronkwo N, Adagunodo RE, 2009. Spatial predictive model for malaria in Nigeria. $\mathrm{J}$ health informatics dev ctries 3.

Kalu MK, Obasi NA, Nduka FO, Otuchristian G, 2012. A comparative study of the prevalence of malaria in Aba and Umuahia urban areas of Abia State, Nigeria. Res J Parasitol 7:17-24. doi:10.3923/jp.2012.17.24

Kazembe LN, Mathanga DP, 2016. Estimating risk factors of urban malaria in Blantyre, Malawi: A spatial regression analysis. Asian Pac J Trop Biomed 6:376-81. doi:10.1016/j.apjtb.2016. 03.011

Keranen K, Kolvoord R, 2017. Making Spatial Decisions Using ArcGIS Pro: A Workbook. Esri Press Redlands, California.

Kincaid C, 2005. Guidelines for selecting the covariance structure in mixed model analysis. Paper presented at the Proceedings of the thirtieth annual SAS users group international conference Available from: https://support.sas.com > papers > proceedings > proceedings > sugi30(accessed Jan. 2019)

Kreuels B, Kobbe R, Adjei S, Kreuzberg C, von Reden C, et al., 2008. Spatial variation of malaria incidence in young children from a geographically homogeneous area with high endemicity. J Infect Dis 197:85-93. doi:10.1086/524066

Laird NM, Ware JH, 1982. Random-effects models for longitudinal data. Biometr 38:963-74. doi:10.2307/2529876

Machault V, Vignolles C, Pagès F, Gadiaga L, Gaye A, et al., 2010. Spatial heterogeneity and temporal evolution of malaria transmission risk in Dakar, Senegal, according to remotely sensed environmental data. Malaria J 9:252. doi:10.1186/1475-28759-252

McCulloch CE, Searle SR, 2001. Generalized Linearand Mixed Models. Wiley Series in Probability and Statistics. Wiley \& Sons, New York, United States. doi:10.1002/0471722073

NMC P, 2015. Nigeria Malaria Indicator Survey Final Report Abuja, Nigeria: Federal Republic of Nigeria. Available from: https://dhsprogram.com/pubs/pdf/MIS20/MIS20.pdf Accessed: January 2019.

Nigeria Demographic Health Survey (NDHS), 2016. Demographic and health survey 2016. DHS Program ICF. Available from: https://dhsprogram.com/data/available-datasets.cfm. Accessed: Jan 2019.

Nelder JA, Wedderburn RWM, 1972. Generalized linear models. J R Stat Soc Ser A 135:370-84. doi:10.2307/2344614

Njau JD, Stephenson R, Menon MP, Kachur SP, McFarland DA, 2014. Investigating the important correlates of maternal education and childhood malaria infections. Am J Trop Med 91:50919. doi:10.4269/ajtmh.13-0713

Okeke TA, Okeibunor JC, 2010. Rural-urban differences in healthseeking for the treatment of childhood malaria in south-east Nigeria. Health policy 95:62-8. doi:10.1016/j.healthpol. 2009.11.005

Okonko IO, Soleye FA, Amusan TA, Ogun AA, Udeze AO, et al., 2009. Prevalence of malaria plasmodium in Abeokuta, Nigeria. Malaysian J Microb 5:113-8. doi:10.21161/mjm.16509

Onwuemele A, 2014. An assesment of the spatial pattern of malaria infection in Nigeria. Int J Med Med Sci 6: 80-6. doi:10.5897/ IJMMS2013.1006 
Onwujekwe O, Uzochukwu B, Dike N, Okoli C, Eze S, Chukwuogo O, 2009. Are there geographic and socio-economic differences in incidence, burden and prevention of malaria? A study in southeast Nigeria. Int J Equity Health 8:45. doi:10. 1186/1475-9276-8-45

Onyiri N, 2015. Estimating malaria burden in Nigeria: a geostatistical modelling approach. Geospat Health 10.306. doi:10.4081/ gh.2015.306

Samadoulougou S, Maheu-Giroux M, Kirakoya-Samadoulougou F, De Keukeleire M, Castro MC, Robert A, 2014. Multilevel and geo-statistical modeling of malaria risk in children of Burkina Faso. Parasites vectors 7:350. doi:10.1186/17563305-7-350

Stroup WW, 2012. Generalized linear mixed models. Modern concepts, methods and applications. CRC press.

Stroup WW, Baenziger PS, Mulitze DK, 1994. Removing spatial variation from wheat yield trials: a comparison of methods. Crop Sci 34:62-6. doi:10.2135/cropsci1994.0011183X003 400010011x

Umer M, Zofeen S, Majeed A, Hu W, Qi X, Zhuang G, 2018. Spatiotemporal Clustering Analysis of Malaria Infection in Pakistan. Int J Environ Res Public Health 15:1202. doi:10.3390/ijerph15061202

UN, 2018. Malaria and the UN Sustainable Development Goals (SDGs) 2030. Available from: https://www.swissmalariagroup.ch/fr/assets/uploads/files/New\%20factsheet $\% 20$ Malaria $\% 20$ and $\% 20$ the $\% 20$ UN\%20Sustainable $\% 20$ Development $\% 2$ 0Goals\%20x.pdf_Accessed: October 2020
Verly G, David M, Journel AG, Marechal A. (eds.), 2013. Geostatistics for natural resources

characterization. Springer Science \& Business Media, New York, United States. doi:10.1007/978-94-009-3699-7

Weli VE, Efe SI, 2015. Climate and epidemiology of malaria in Port Harcourt Region, Nigeria. AJCC, 4:40. doi:10.4236/ajcc. 2015.41004

WHO, 2018. World malaria report 2018. Geneva, Switzerland. Available

from: https://www.who.int/malaria/publications/world-malariareport-2018/en/ Accessed: June 2019.

WHO, 2019. Global technical strategy for malaria 2016-2030. Available from: https://www.who.int/malaria/areas /global_ technical_strategy/en/ Accessed: October 2020)_

WHO, 2015. Guidelines for the treatment of malaria - Third edition. Available from: https://www.who.int/publications/i/ item/9789241549127 Accessed: January 2019.

Yaya S, Uthman O, Amouzou A, Bishwajit G, 2018. Use of intermittent preventive treatment among pregnant women in subSaharan Africa: Evidence from malaria indicator surveys. Trop Med Infect Dis 3:18. doi:10.3390/tropicalmed3010018

Yusuf OB, Adeoye BW, Oladepo OO, Peters DH, Bishai D, 2010. Poverty and fever vulnerability in Nigeria: a multilevel analysis. Malaria J 9:235. doi:10.1186/1475-2875-9-235

Zimmerman DL, Harville DA, 1991. A random field approach to the analysis of field-plot experiments and other spatial experiments. Biometr 47:223-39. doi:10.2307/2532508 